Hydrol. Earth Syst. Sci. Discuss., https://doi.org/10.5194/hess-2017-504

Manuscript under review for journal Hydrol. Earth Syst. Sci.

Discussion started: 29 August 2017

(c) Author(s) 2017. CC BY 4.0 License.

\title{
Comparison and validation of eight satellite rainfall products over the rugged topography of Tekeze-Atbara Basin at different spatial and temporal scales
}

\section{4}

Tesfay G. Gebremicael ${ }^{1,2,3}$, Yasir A. Mohamed ${ }^{1,2,4}$, Pieter van der Zaag ${ }^{1,2}$ Amdom G. Berhe $^{5}$, Gebremedhin G. Haile ${ }^{3}$, Eyasu Y. Hagos ${ }^{5}$, Mulubrhan K. Hagos ${ }^{3}$

${ }^{1}$ IHE Delft Institute for Water Education, P.O. Box 3015, 2601 DA Delft, The Netherlands

${ }^{2}$ Delft University of Technology, P.O. Box 5048, 2600 GA Delft, The Netherlands

${ }^{3}$ Tigray Agricultural Research Institute, P.O. Box 492, Mekelle, Ethiopia

${ }^{4}$ Hydraulic Research Center, P.O. Box 318, Wad Medani, Sudan

${ }^{5}$ Mekelle University, P.O. Box 231, Mekelle, Ethiopia

Correspondence to:T.G. Gebremicael(t.gebremicael@un-ihe.org/dutg2006@gmail.com)

\section{Abstract}

Satellite rainfall products are considered important options for acquiring rainfall estimates in the absence of ground measurements. However, estimates from these products need to be validated as their accuracy can be affected by geographical position, topography, and climate, as well as by the algorithms used to derive rainfall from satellite measurements. Eight satellite-based rainfallproducts (TRMM, CHIRPS, RFEv2, ARC2, PERSIANN, GPCP, CMAP and CMORPH) were evaluated against ground observations over the complex topography of the upper Tekeze-Atbara basin in Ethiopia. The performance was evaluated at various temporal (daily, monthly, seasonal) and spatial (point, sub-basin, basin) scales over the period 2002-2015.

6 Results show thatCHIRPS, TRMM,and RFEv2 performed well and wereable to capture the rainfall measured by rain gauges. The BIASand correlation of these products were within $\pm 25 \%$ and $>0.5$ over different time steps. The remaining products poorly performed at daily time step with higher BIAS (up to $\pm 200 \%$ ) and lower correlation $(<0.5)$. CMORPH, PERSIANN, and ARCv2 were relatively better while CMAP and GPCP performed poorly $(r<0.4)$ in all conditions. The overall performance of all products was lower in the mountainous areas of the basin with station elevation $>2500$ m.a.s.l. Compared to the lowlands, the BIAS at highlands increased by $35 \%$ whilst the correlation dropped by $28 \%$.

Underestimation and overestimation of rainfall dominated in the mountainous and lowland areas, respectively.CMORPH and TRMM overestimated while the remaining products underestimated the rainfall at all spatiotemporal scales. CMAP, ARC2, and GPCP estimates were the most affected by large underestimation. Unlike in temporal scale, the performance of the products did not show a uniform pattern with respect to spatial scale.Their performance improved from point to aerial comparisons in the lowlandswhereas it slightly reduced athighland areas. Poor performance in the highlands contributed to a slightly lower performance at basin scale compared to thepixel-to-pointcomparison.

2 Our results showthat rainfall estimates from CHIRPS and TRMM have a consistently good agreement with ground rainfall at different spatiotemporal scalesin the upper Tekeze-Atbara basin. Interpolating the sparse and unevenly distributed rain gauges over the complex terrains however introduces unknown uncertainties with respect to the actual rainfall.

Keywords:Rainfall estimation,Satellite products, validation, Nile River Basin, Ethiopia 


\section{Introduction} water management, hydrological applications, and agricultural forecasts (Guo \& Liu, 2016;

Accurate information on rainfall data is necessary for many operational and research fields of Sunilkumar et al., 2015). It is arguably considered as the most important driving force for any hydrological model. Despite its importance for socioeconomic development, ground-based rainfall measurements are sparse and unevenly distributed,especially in developing countries(Behrangi et al., 2011; Gebremichael et al., 2014). The recommended density of ground rainfall measuring network in tropical regions is one gauge per $600-900 \mathrm{~km}^{2}$ for flat and $100-250 \mathrm{~km}^{2}$ for mountainous areas, respectively (WMO, 1994). However, such densities are not available in most tropical regions (Taye \& Willems, 2013; Worqlul et al., 2014). Due to different limiting factors, including climatic conditions and human geography, ground rainfall stations are sparse or do not exist at the required temporal and spatial scales (Meng et al., 2014). Recently, satellite rainfall products are considered as important alternative options for acquiring rainfall estimates. These products are advantageous in terms of temporal and spatial coverage and providing data sources in ungauged basins (Dinku et al., 2014; Katsanos et al., 2016).

Satellite rainfall products are increasingly available with almost global coverage and the supply of those products are becoming cost effective sources for hydrological applications (Menget al., 2014; Thiemig et al., 2012). The spatiotemporal resolutions and measurement accuracy of these products are continuously improving because of advancement in sensor technologies and estimation techniques. A number of higher resolution rainfall products are now available at a quasi-global scale (Behrangi et al., 2011; Jiang et al., 2012). The Tropical Rainfall Measurement Mission (TRMM), African Rainfall Estimation (RFE), African Rainfall Climatology (ARC), Global Precipitation Climatology Project (GPCP), Precipitation Estimation from Remotely Sensed Information using Artificial Neural Networks (PERSIANN)Climate Hazards Group InfraRed Precipitation with Stations (CHIRPS) and CPC Morphic technique (CMORPH) are among the common products that have been widely applied.

However, satellite rainfall products need to be validated as their accuracy can be affected by geographical position, topography, and climate, as well as by the algorithms used to derive rainfall from satellite measurements(Meng et al., 2014; Xue et al., 2013). Several studies on the validation and comparisons of these products with ground measurements have been 
conducted at different scales (e.g. Dinku et al., 2007; Feidas, 2010; Guo \& Liu, 2016; Nevertheless, the performance varies among the rainfall products because of different data sources and retrieving algorithms (Derin \& Yilmaz, 2014; Toté et al., 2015). In addition, the performance also varies for the same data type across different regions and seasons (Gebremichael et al., 2014; Hu et al., 2014). This indicates that the performance of satellite products largely depends on the location, topography, season, and hydro-climatic characteristics of the study area. Therefore, the reliability of satellite rainfall needs to be validated and compared against ground measurements to a specific area and temporal scales before it can be used in any subsequent application (Feidas, 2010; Ouma et al., 2012).

Validation and inter-comparison of different rainfall products over the complex topography of the upper Tekeze-Atbara (T-A) basin are essential to determine which product is representative. A number of studies have been conducted in Ethiopia to evaluate different satellite rainfall products (e.g., Dinku et al., 2007; Gebremichael et al., 2014; Haile et al., 2013; Worqlul et al., 2014; Beyissa et al., 2017). However, these studies have mainly focused on the Upper Blue Nile basin and to some extent on central Ethiopia. In the T-A basin, where these products can contribute to better understanding of catchment response to land degradation and environmental rehabilitation programs, there has been no comprehensive validation studies. Therefore, this studywas intended to validate eight of the widely used satellite rainfall products on different spatiotemporal scales. The relationships between satellite rainfall products and topography were also carefully explored in order to understand possible errors produced by the rugged terrains.

\section{Study area and Data}

\subsection{Study area}

This study was conducted in the Upper T-A basin, one of the main tributaries to the Nile river located in the Northern Ethiopia, with a total catchment area of $45,694 \mathrm{~km}^{2}$ at the outlet. It is situated between $37.5^{\circ}-39.8^{\circ} \mathrm{E}$ and $11.5^{\circ}-14.3^{\circ} \mathrm{N}$ (Fig.1). The basin is characterized by rugged topography with a significant variation ranging from 833 to 4530 m.a.s.l. About $0.2 \%$, $52 \%, 42 \%$ and $0.62 \%$ of the land is found below 1000, between 1000-2000, 2000-3000, 3000-

324000 and above 4000 m.a.s.l, respectively. This clearly indicates that topography is a key factor in influencing microclimates in the basin. 
2 Figure 1: Location map and distribution of rainfall stations in the Upper T-A Basin The basin is characterized by a semi-arid climate in the east and north and partly semi-humid in the south (Belete, 2007). More than $85 \%$ of the total annual rainfall falls in the wet season (June -September) which varies from $400 \mathrm{~mm} \mathrm{yr}^{-1}$ in the east to more than $1200 \mathrm{~mm} \mathrm{yr}^{-1}$ in

6 the south (Fig. 2a). The variations are mainly associated with the seasonal migration of the inter-tropical convergence zone (ITCZ).The beginning and ending of the ITCZ over highlands of Ethiopia varies annually, which mostly causes the inter-annual rainfall variability (Selshi\&Zanke, 2004;Nyssen et al., 2005).

The general pattern of rainfall over the basin isalso modified by the complex topography (Dinku et al., 2007; Viste \& Sorteberg, 2013).This implies that the movement ofair moisture is substantially modified to create contrasting rainfall regimes in the region (Huber et al., 2006).

The sudden changes in elevation can obstruct the air mass movement to create a microclimate at the bottom of mountains or can updraft over the mountains to create orographic rainfall (Dinku et al., 2007).

In most regions, rainfall increases with elevation due to the orographic uplifts (Moreno et al., 2014; worqlul et al., 2014). However, this relationship is not uniform in the T-A Basin (Fig.2b). Rainfall in the mountains is higher in some areas and lower in others (Kiroset al., 2015). Figure $2 \mathrm{a}$ indicates that the total annual rainfall increases with elevation in the southern and southwestern parts of the basin only. In contrast, it reduceswith elevation in most other parts of the basin.Stations located in the highlands of the eastern and northern parts of the basin receiveless rainfall compared to the associated lowlands (Fig. 2a). This is attributed to the complex local topography, which alters proximity to the sources of moist air and seasonal movementsof the ITCZ (Van der Entet al., 2010; Kiros et al., 2016).

During the rainy season, the ITCZ moves towards the Northern part of the basin, which brings moisture from the Atlantic and Indian oceans through westerly (Degefu et al., 2016; Mohamed et al., 2005). When the rain-bearing winds reach the basin, their direction is modified by the local topography forcing the release of moisture in the lower areas before they reach the top of mountains. This creates more intense and shorter duration convective rainfall events in the lowlands where warm and moist airflows encounter the mountain foothill. Van der Ent et al. (2010)showed that topography can play an important role in 
moisture cycling either by blocking or capturing moving air masses. Another possible reason

\subsection{Datasets} bearing winds are stronger, they carry less water vapour (Viste \& Sorteberg, 2013). The nonuniform patterns of rainfall against the topography can strongly influence the performance of satellite rainfall estimates (Haile et al., 2013).

Figure 2: Relationship between rainfall and elevation in the T-A basin

\subsubsection{Rain gauge data}

Ground rainfall data used for validation of the satellite products comprised of 34 stations located within and surrounding the basin (Fig.1). These data were provided by the Ethiopian Meteorological Service Agency (NMA). The datasets coverdaily data for the period from 2002 to 2015. Although the number of stations is relatively good, their distribution over the basin is not uniform. Most of the gauges are located in easily accessible areas and the distribution of gauges in the lowland areas are sparse (Fig. 1). Interestingly, most of the rainfall stations with a relatively good quality of data are located in the highland areas where the spatial variability of rainfall is very high.A summary of these ground measurements with vertical locationsis given as an electronic supplementary file (Table S1).

Quality control of rainfall data from each station was done to identify if there were outliers and missing values. All outliers were then compared to neighbouring gauges to cross-check if observed extreme values resulted from extreme climate events. Stations with large data gaps in between the selected validation period were excluded from the analysis. After data screening, 34 stations out of the 75 in the basin were found to be reliable with a relatively consistent record.

\subsubsection{Satellite rainfall products}

The validation and inter-comparison of eight satellite rainfall products were performed atdaily, monthly, and seasonal scales. Table 1 provides the summary of satellite rainfall products used for this study. These products were selected based on their public domain and long-term data available, spatiotemporal resolution, near-real-time availability and their common applications in Africa (Dembélé \& Zwart, 2016; Dinku et al., 2007; Thiemig et al., 2012). 
Table 1: Summary of selected satellite rainfall products for this study (in descending order of spatial

2 resolution)

4 The CHIRPS datasets, developed by the US Geological Survey (USGS) and the Climate Hazards Group at the University of California are blended products which combine global climatologies, satellite observations and in-situ rainfall observations from Global Telecomunications system (GTS) (Funk et al., 2014; Knapp et al., 2011). CHIRPS incorporates $0.05^{\circ}$ resolution satellite rainfall estimates with in-situ station data to produce daily time series (Katsanos et al., 2016).

10

$\mathrm{ARCv} 2$ is produced by the National Oceanographic and Atmospheric Administration Climate Prediction Center (NOAA-CPC) and provides daily rainfall data over Africa. It is very similar to RFEv2 except the 30 minutes is replaced by the 3-hourly IR data (Love et al., 2004).

The RFEv2 is also provided by NOAA-CPC for Famine Early Warning Systems Network to assist in disaster-monitoring activities over Africa (Herman et al., 1997). RFEv2 has been operational since 2001 and uses rainfall estimates from PM sensors, IR data from METEOSAT and daily rainfall from the GTS reports. Daily rainfall estimates were obtained at $0.1^{\circ}$ spatial resolution by merging these sources.

20

The CMORPH product that produces global rainfall analysis at a very high spatial and temporal resolution is also a product from NOAA-CPC. Unlike the other products, the CMORPH product is not an algorithm for merging of the PM and IR estimates rather it uses the IR information for the spatial and temporal evolution of clouds, not the rainfall estimates (Asadullah et al., 2008; Joyce et al., 2004). It uses rainfall estimates derived from low orbit PM observations and propagate these features using a high temporal and spatial resolution IR data (Joyce et al., 2004). According to Dinku et al. (2007), the CMORPH combines the superior retrieval accuracy of the PM and higher resolution of IR data. This method is highly flexible as it allows incorporation of any rainfall estimate from PM satellites.

The PERSIANN precipitation estimates were developed by the Center for Hydrometeorology and remote sensing atthe University of California (Ashouri et al., 2015). It uses an artificial neural network approach to merging the IR and PM data and the rainfall estimates are based on the infrared brightness temperature image provided by geostationary satellites (Hsu et al., 
1997). The rainfall estimates in PERSIANN algorithm are available at $0.25^{\circ}$ spatial

2 resolution.

4 The latest version of TRMM product (3B42V7) was developed by the National Aeronautics and Space Administration (NASA). This product was obtained from the TRMM Multisatellite precipitation analysis (TMPA) algorithm which combines Infrared (IR) and Passive Microwave (PM) data retrievals (Guo \& Liu, 2016; Huffman et al., 2007). TRMM rainfall estimates incorporates gauge data for bias correction from several sources including national and regional meteorological services. (Funk et al., 2014). The TRMM3B43 rainfall products were agreggated from the TRMM3B42 3-hourly estimates and merged with station data to produce daily rainfall (Dinku et al., 2007).

12

The GPCP is a blended product which combines the Global Precipitation Climatology Center (GPCC) gauge data with the PM and IR rainfall estimates (Huffman et al., 1997). The PM estimates in this product are based on the Special Sensor Microwave /Imager (SSM/I) data from the Defence Meteorological Satellite program (DMSP, US) while the IR data came mainly from Geostationary Operational Environmental Satellite (GOES) Precipitation Index (PI) (Xie \& Arkin, 1995). This technique is advantageous as it combines rainfall estimate information from many data sources by taking the strength of each data type.

20

CMAP products include monthly and pentad (5-day) mean rainfall estimates at $2.5^{\circ}$ spatial resolution (Feidas, 2010). These techniques produce rainfall estimates by merging ground station data with rainfall estimates from several satellite-based algorithms (Xie \& Arkin, 1997). As described in Xie and Arkin (1997), inputs are derived by combining of geostationary and polar orbiting infrared, PM retrievals and rain gauge observations. First, the IR and PM rain estimates are merged using a maximum likelihood approach where the estimate with weights are derived by comparison to the gauge analysis. Then, the gauge analysis is used to obtain an absolute value of the merged product (Feidas, 2010).

\section{Methodology}

\subsection{Validation processes}

32 The spatial patterns of eight satellite products were evaluated and compared with rain gauge data at daily, monthly, and seasonal scales. Both the satellite and gauge rainfall data were 
collected at different temporal scale and first, the daily data were aggregated to monthly and

2 (June-September) (Gebremicael et al., 2017), seasonal comparison was considered only for this period. The ability to replicate the observed rainfall by the products was done during this common period between all satellite and station rainfall. Considering the given climatic variability, complex topographical characteristics and hydrological working units of the basin, the performance of these products were evaluated using two approaches, namely point-topixel and aerial averaged rainfall comparison.

Rainfall over a complex topography like the T-A basin is largely subjected to small-scale variability, which implies that evaluation of such satellite products should be at the smallest possible spatial and temporal scales (Thiemig et al., 2012). Accordingly, in the first approach all satellite rainfall products from the corresponding grid cell were compared to the ground observed data within the satellite box. The variance of satellite estimate is smoother in space and time as these products are represented by the spatial averages over the pixels. For this analysis, the satellite rainfall products were extracted for the location of each rainfall station and their performance were evaluated using statistical indices. It was assumed that the amount of point rainfall is uniform in the area of the pixel which may not necessarly true. The second approach was based on the aerial rainfall comparison at different spatial scales. Representative sub-basins from lowland and highland areas (Fig.1) with an average elevation of 1400 and 3000 m.a.s.l.were considered in order to account for the effect of topography.

22 Satellite products were validated at sub-basin and basin level by comparing spatially aggregated pixel values against a corresponding interpolated observed rainfall from gauge stationsusing the inverse distance weighting (IDW) method (Ruelland et al., 2008).

\subsection{Evaluation statistics}

The satellite rainfall products were quantitatively evaluated against ground observations using four statistical indices:the relative percent of bias (PBIAS), Pearson correlation coefficient (r), Root Mean Square Error (RMSE), and Mean Absolute Error (MAE) Table 2). A detailed description of these indices can be found in Toté et al. (2015) and Thiemig et al. (2012).

Table 2: Statistical indices used for the satellite rainfall products performance evaluation

Where $\mathrm{xi}$ is observed rainfall from raingauge, yi is satellite rainfall product, $\mathrm{N}$ is the number of pairs of products,

$34 \bar{x}$ and $\bar{y}$ are the average of observed and satellite rainfall data, respectively. 
2

Agreement between estimates and observation is considered satisfactory for PBIAS and $\mathrm{r}$ values $\pm 25 \%$ and $>0.5$, respectively (Moriasi et al., 2007). The lower the RMSE and MAE values, the closer the satellite estimates are to the ground measurements. The unit of RMSE and MAE is $\mathrm{mm} /$ time period.

\section{4. Results and discussion}

\subsection{Comparison at pixel-to-point spatial scale}

8 The performance of satellite estimates was evaluated by comparing these data for 34 rainfall stations at grid level covering the location of the station. Comparisons were carried out at daily, monthly, and seasonal periods. First, dailyrainfall of eight products was compared with the observed daily rainfall. Figure 3 shows the PBIAS (\%) and correlation (r)of all satellite estimates against ground station values. The daily estimates performed poorly in the majority of stations. However, CHIRPS, RFEv2 and TRMM had a relatively good performance with lower PBIAS, RMSE and MAE and higher r compared to other products (Fig.3 andTables S2and S3). The average value of PBIAS for all stations were $-13 \%,-16 \%$ and $17 \%$ for CHIRPS, RFEv2 and TRMM, repectively. Similarly, $r$ value of these products was $\geq 0.5$ in the majority of stations with an average value of $0.52,0.50$ and 0.50 , respectively.. The RMSE and MAE, which evaluates the average magnitude error between satellite estimates and ground stations showed the same trend as PBIAS and $\mathrm{r}$ (Tables S2 and S3). The remaining products failed to capture the observeddaily rainfall with correlationof $<0.5$ and higher PBIAS, RMSE and MAE in most stations (Tables S2 and S3). The ARC2, GPCP and CMAP performed poorly.

The precision of these products to reproduce the observed rainfall wasfurther investigatedat monthly time series. Table 3 shows the average value of accuracy indicators obtained by comparing each product with ground stations. The results indicate thatthe performance of all products improvedwhen daily data are aggregated to monthly data. The correlationfor CHIRPS, RFEv2 and TRMM were $>0.5$ in all stations with an average value of $0.61,0.59$ and 0.56, respectively (Table3). Similarly, the PBIAS value reducedat monthly time scale.The RMSE and MAE indices also decreased at monthly scale, which implies the agreement between satellite and ground rainfall increased (Table 3).Forexample, Fig. 4 compares the pattern of statistical indices for all products in four representative (highland, lowland and 
medium) stations. CHIRPS, RFEv2 and TRMM outperformed to the other products. ARCv2, CMAP and GPCP again performed poorly with a $r<0.5$ and higher PBIAS (Table 3 ).

4 Figure 3: Comparison of daily satellite rainfall estimate with ground measurements, (a) PBIAS, (b) Correlation (r)

6

Table 3: Average accuracy indicators obtained from monthly comparison

Moreover, comparisons based on average monthly point rainfall (2002-2015) at the given locations indicate that rainfall estimates of CHIRPS, RFEv2 and TRMM products agree with the corresponding ground measurements (Fig.5). Monthly rainfall patterns from these products have a consistent and strong agreement with the ground rainfall compared to the remaining products.

To gain further information on the seasonal variations of rainfall estimate skills of the satellite products, comparisons were also madefor the entire rainy season (June-September). Figure 6 presents an inter-comparison of wet season rainfall estimates with the observed rainfall of the same period. The spatial distribution of correlationcoefficients (Fig. 6) and PBIAS (Fig.S1) show patterns that are similar to these ofthe daily and monthly results. However, the performance of all products was significantly improved during the wet season. Six satellite products had an excellent agreement with ground rainfall (CHIRPS, TRMM, PERSIANN, RFEv2, ARC2, and CMORPH) during the wet season.CHIRPS, RFEv2, and TRMM correlated best with the observed rainfall compared to the remaining products. With average values of $0.84,0.74$, and 0.75 for CHIRPS, RFEv2, and TRMM, respectively, the correlation coefficient of these products showed a strong agreement. The PBIAS of these productswas also within the range of $\pm 25 \%$ in most stations. The RMSE and MAE indices were also lower than the other products (Tables S4 and S5). Next, the PERSIANN, CMORPH and ARCv2 products showed a good agreement with the gauged rainfall. Improved correlation $(r>0.5)$ and lower PBIAS, RMSE and MAE were obtained in $80 \%$ of the stations, however the GPCP and CMAP products continued to show poor agreement despite some improvements (Fig. 6 and Tables S4 and S5).

Figure 4: Monthly statistical indices at pixel to point rainfall comparison. 

ground stations

Point-to-pixel comparison of the different temporal scales showed that all satellite products suffer from both over and underestimations, explained by negative and positive values of PBIAS.Both phenomena were observed in all products at several locations and time scales.TRMM and CMORPH systematicaly overestimate the rainfall in more than 20 stations while they underestimate rainfall in the remaining stations. The RFEv2, GPCP, ARC2 and CMAP products consistently underestimate rainfall in the majority of ground stations. Most overestimations(underestimations) were observed during the dry (October-May) (wet (JuneSeptember)) months (Fig.5). However, the performance of all products to capture the observed rainfall were better in the dry months. This is due to the reduced probability of rainfall during the dry months.

Figure 6: Spatial distribution of correlationcoefficients (r) during the wet season comparison.

It is also important to remark that inconsistent estimation of rainfall by all products is likely due to the effect of rugged terrains. The overall performance of the satellite rainfall products is lower in the peripheries of the basin where most stations are located in the mountainous area with an elevation> 2,500 m.a.s.l. (Fig.7). As shown in Fig. 4, lower correlation and higher PBIAS is observed in Debark compared to Sekota with an elevation of 3,000 and 1,960 m.a.s.l., respectively.A relatively better performance occurred in central, eastern, and northwestern parts of the basin where stations are located below 2,500 m.a.s.1. As an example, the long-term annual observed and satellite rainfall from CHIRPS were plotted against elevation of stations (Fig.7). The graph clearly shows that the relationship pattern of rainfall with elevation is not straightforward. The correlation of these products showed a poor agreement at higher elevation.A similar study in the neighbouring Upper Blue Nile basin by Gebremichaelet al.(2014) also showed that satellite products failed to capture the ground rainfall in mountainous compared to lowland areas. This result is consistent with other studies carried out elsewhere(e.g. Asadullah et al., 2008; Derin \& Yilmaz, 2014; Guo \& Liu, 2016;

Hu et al., 2014) 
In summary, the combination of daily, monthly, and seasonal point comparisons demonstrate that the CHIRPS, RFEv2, TRMM, and PERSIANN products have the best agreement with the observed rainfall across the basin. The evaluation indices at different time scales and average monthly plots comparison show that CHIRPS performs best, followed by RFEv2 and TRMM. Over- and under-estimation of daily, monthly and seasonal rainfall by CHIRPS was smaller compared to the other products.

\subsection{Comparison based on aerial averaged rainfall}

Spatiotemporally aggregated aerial rainfall of each product was also compared with the corresponding interpolated rainfall from the gaugesat daily, monthlyand seasonal time scales.

Table 4 shows the performance of all products at basin level anddifferent time scale. Similar to the point-to-pixel comparison, the CHIRPS, RFEv2, TRMM, PERSIANN, and CMORPH aerial rainfall estimates had the best accuracy, with PBIAS within $\pm 25 \%$ at all temporal scales. However, all products showed a lower performance in terms of correlation with $<0.5$ and higher RMSE and MAEat daily compared to monthly and seasonal time scales. Lower performance at daily scale can be explained by erroneous (non-detection) of more localized convective rainfall events. The CMAP,ARCv2, and GPCP continued to show lower $\mathrm{r}$ and higher RMSE, MAE and PBIAS consistently atall time scales. The performance improved at monthly and seasonal scales (Table4). Higher accuracies at larger time scales are due to the fact that the errors at smaller time scale are symmetrical and offset each other when aggregated.

The negative and positive values of PBIAS in Table 4 confirms that most products underestimated rainfall during the wet season, except TRMM and CMORPH. Figure 8 shows the visual comparison of the long-term monthly aerial average of satellite estimates with the corresponding ground aerial rainfall. It clearly indicates that the TRMM and CMORPH products consistently overestimated, whereas CMAP, GPCP and ARC2 underestimated rainfall in all months. The remaining products showed a varied picture for the different months. For example, CHIRPS and RFEv2 slightly underestimatedrainfall during the rainy months of July and August whilst overestimatingrainfall in the dry months (Fig.8).Duringthe 
Table 4: Comparison of satellite and observed aerial rainfall, at basin scale, at different time scales

2

Figure 8: Monthly average satellite estimates and ground rainfall comparison at basin scale

$4 \quad$ Whereas all satellite rainfall estimates showed a consistent improving pattern with increasing time scale, their performance did not show a uniform pattern with increasing spatial scale.Figure9 shows a compares average correlation of the products at different spatial scales forthe wet season. Most products performed worse at basin scale compared to pixel-to-point and lowland sub-basin scales. The likely reason is that the aerial averaged rainfall over the complex topography suffers from limitations due to the uneven distribution of rain gauges. The performance of CHIRPS, TRMM, and CMAP improved at basin level compared to pixelto-point scale whilst all other products performed worse(Fig.9). The relatively poor 12 performance at the basin scale for most products is likely due to the topographical variations across the basin. Variations of topography can significantly compromise the interpolation of observed rainfall (Thiemig et al., 2012). The rainfall stations are also sparsely and unevenly distributed over the basin, which can be a source of systematic errors when interpolating aerial rainfall (Dembélé \& Zwart, 2016; Toté et al., 2015).

To further understand the effect of complex terrains on the performance of the satellite products, the seasonal aerial rainfall of representative highland and lowland sub-basins was compared (Fig.9). The result ofthe two contrasting topographic featuresdemonstrates that theoverall correlation of satellite rainfall estimates is better in lowland than in high mountainous areas. This suggeststhat the satellite products may not accurately capture the spatial pattern of seasonal rainfall in complex topographic areas like the T-A basin. Further,

24 all products overestimate rainfall in the lowlands and underestimate rainfall of the rain in the highlands.However, comparing both topographic features, the magnitude of underestimation was greater than that of overestimation in most products. For example, CHIRPS, TRMM, and CMORPH underestimated the wet season rainfall over the highland area by 32,28 , and $52 \%$, while it overestimated by 18,21 , and $28 \%$ the lowland rainfall, respectively.

Fig.9: Comparison of seasonal averaged correlation at a pixel, sub-basin, and basin scales

32 In summary, based on the comprehensive evaluation at different temporal and spatial scales, the CHIRPS, RFEv2, and TRMM outperformed the other satellite rainfall products at all 

to considers topographic effects and its high spatial resolution (Katsanos et al., 2016). The good performance ofTRMM,and RFEv2 is possibly due to the fact that these productshave a bias correction that is based rain gauge data (Thiemig et al., 2012).

6 Our findings are in agreement withsimilar studies (e.g. Dembélé \& Zwart, 2016; Hessels, 2015; Katsanos et al., 2016; Bayissa et al., 2017; Dinku et al., 2008). Hessels (2015) compared 10 satellite products over the Nile basin and CHIRPS and TRMM werefound to be the best-performing products.Bayissaet al. (2017)revealed that CHIRPS estimates showed better performance than PERSSIAN and TARCAT over the Upper Blue Nile basin. Similarly, Gebremichaelet al. (2014) and Dinkuet al. (2007)showedthat CMORPH and TRMM well performed in the rugged terrains of neighbouring basin.Next tothese products, CMORPH, PERSIANN, and ARCv2 were better in capturing the observed rainfall while CMAP and

14 GPCP poorly performed at all spatiotemporal scales.Dinku et al. (2007) also showed that CMAP and GPCP products poorly performed compared to TRMM and CMORPH in Ethiopia.

18 The performance of all products consistently correlated best with ground measurements when aggregated at larger time scales. Improved performance with increasing time step is obviously due to counterbalancing of variabilities when accumulated from smaller to larger time scales. Many studies (e.g. Dembele\&Zewart, 2016; Guo\& Liu, 2016; Menget al., 2014)reported that the performance of satellite estimates improved as time step increased. In contrast, the performance of these products wasnot uniform with an increasing spatial scale. The performance of all products increased from point rainfall to aerial rainfall in the lowlands, whereas their performance decreased in thehighlands (Fig.9). Apoorer performance in the mountainous area is notable for all products. This result is in agreement with other studies (e.g. Derin and Yilmaz; 2014; Dinku et al., 2007)whichindicates that satellite rainfall products have challenges to estimate orographic precipitation in basins with a complex topography.

\section{Conclusions and Recommendations}

30 This study evaluated the performance of eight-satellite based rainfall products ranging from high to low resolution over the T-A basin. These products were evaluated and compared withground stations during 2002-2015. A comprehensive approach was applied that includedpoint-to-pixel and aerial averaged comparisons at different spatialand temporal scales 
(daily, monthly, and seasonal). The relationship between rainfall and elevation wasalso analysed to identify the effects of topography on the performance.

4 The results showed that the CHIRPS, RFEv2, and TRMM rainfall estimates outperformed the other products consistently across all temporaland spatial scales. These products achieved acceptable correlation coefficients $(>0.5)$ and PBIAS, RMSE and MAEvalues for both approaches and at all time scales. The PBIAS of these products were within $\pm 25 \%$ atall timescales. CMORPH, PERSIANN, and ARC2 achieved lower scores. The performance of CMAP and GPCP was poor over the various conditions with PBIAS ranging from $-250 \%$ to

$10118 \%$ and correlation $<0.5$. A relatively lower performance is notable for all products in the mountainous areas.

12 The agreement between the products and rain gauge improved with increase in time scale. This is due to the fact that errors at smaller time scales offset each other when aggregated. All satellite estimates suffered from under- and over-estimation during the different time and spatial scales. Underestimation dominated in the mountainous areas. TRMM and CMORPH overestimated rainfall whilst the remaining products underestimated rainfall consistently at all spatiotemporal scales.CMAP, ARC2, and GPCP estimates were the most affected by large underestimations across all stations. Another key finding of this study isthat unlike in time, the performance of the products did not show a uniform pattern at different spatial scales. The performance improved when increasing the aerial averaged rainfall in the lowlands, whereas it decreased at larger spatial scale in the highlands.Accuracy indicators at point-to-pixel comparison wereslightly better than aerial averaged rainfallin the whole basin.Poor performance over the mountain areas contributed to lower performance at larger spatial scales. Moreover, systematic errors during the interpolation of observed rainfall over the complex topography of the basin might havecontributed to the overall lower performance at the basin scale.

The ranking of these products may not be absolute as validation of these products in different study periods could result in different rankings. Interpolation of the sparse and unevenly distributed rain gauges over complex terrainsmay also introduce significant uncertainties and therefore limits the validity of the result. However, considering the current data availability, the result of this study provides a basis for the utilization of satellite rainfall estimates over the complex topography of the T-A basin. It will be a good reference for future applications of satellite rainfall, especially in rain gauge sparse and ungauged basins with rugged terrains. 
Hydrol. Earth Syst. Sci. Discuss., https://doi.org/10.5194/hess-2017-504

2 Acknowledgement: This study was carried out with the support of the Netherland Fellowship Programme (NUFFIC) and the Tigray Agricultural Research Institute (TARI). The authors would like to thank the Ethiopian National Meteorological Agency for providing the weather data.

6

8

\section{References}

Asadullah, A., McIntyre, N., \& Kigobe, M.: Evaluation of five satellite products for estimation of rainfall over Uganda. Hydrolog. Sci. J., 53(6), 1137-1150, 2008.

Ashouri, H., Hsu, S., Sorooshian, D., Braithwaite, K., Knapp, D., Cecil, B. Prat, C.:PERSIANNCDR:Daily Precipitation Climate Data Record from Multisatellite Observations for Hydrological and Climate Studies. B. Amr. Meteor. Soc., 96(1), 69-83, 2015.

Bayissa, Y., Tadesse, T., Demisse, G., \& Shiferaw, A.: Evaluation of Satellite-Based Rainfall Estimates and Application to Monitor Meteorological Drought for the Upper Blue Nile Basin, Ethiopia. Remote Sens., 9(7), 669, 2017.

Behrangi, A., Behnaz, K., Tsou, C., Amir, A., Kuolin , Soroosh, S., \& Bacchetta, N.: Hydrologic evaluation of satellite precipitation products over a mid-size basin. J. Hydrol., 397 225-237, 2015.

Belete, k.:Sedimentation and Sediment Handling at Dams in Tekeze Riiver Basin, Ethiopia. ( $\mathrm{PhD}$ thesis), Norwegian University of Science and Technology, Trondheim, Norway, 2007.

Dembélé, M., \& Zwart, S. J.: Evaluation and comparison of satellite-based rainfall products in Burkina Faso, West Africa. Int. J. Remote Sens., 37(17), 3995-4014, 2016.

Derin, Y., \& Yilmaz, K. K.: Evaluation of multiple satellite-based precipitation products over complex topography. J. Hydrometeorol., 15(4), 1498-1516, 2014.

Dinku, T., Ceccato, P., Grover-Kopec, E., Lemma, M., Connor, S., \& Ropelewski, C.: Validation of satellite rainfall products over East Africa's complex topography. Int.J.Remote Sens., 28(7), 1503-1526, 2007.

Feidas, H.: Validation of satellite rainfall products over Greece. Theor. Appl. Climatol., 99, 193-216, 2010.

Funk, C. C., Peterson, P. J., Landsfeld, M. F., Pedreros, D. H., Verdin, J. P., Rowland, J. D.,Verdin, A. P.: A quasi-global precipitation time series for drought monitoring. US Geological Survey Data Series, 832(4), 2014.

Gebremicael, T. G., Mohamed, Y. A., v. Zaag, P., \& Hagos, E. Y.: Temporal and spatial changes of rainfall and streamflow in the Upper Tekezē-Atbara river basin, Ethiopia. Hydrol. Earth Syst. Sci., 21(4), 2127-2142, 2017.

Gebremichael, M., Bitew, M. M., Hirpa, F. A., \& Tesfay, G. N.: Accuracy of satellite rainfall estimates in the Blue Nile Basin: Lowland plain versus highland mountain. Water Resour. Re., 50(11), 8775-8790, 2014.

Guo, R., \& Liu, Y.: Evaluation of Satellite Precipitation Products with Rain Gauge Data at Different Scales: Implications for Hydrological Applications. Water, 8(7), 28, 2014.

Haile ,A, Habib, E., \& Rientjes, T.: Evaluation of the Climate Prediction Center (CPC) morphing technique (CMORPH) rainfall product on hourly time scales over the source of the Blue Nile River. Hydrol. Process., 27(12), 1829-1839, 2013.

Herman, A., Kumar, P., Arkin, P., \& Kousky, V.: Objectively Determined 10-Day African Rainfall Estimates Created for Famine Early Warning Systems. Int. J. Remote Sen., 18, 2147-2159, 1997.

Hessels, T. M.:Comparison and Validation of Several Open Access Remotely Sensed Rainfall Products for the Nile Basin. TU Delft, Delft University of Technology, The Netherlands, 2015. 
Hydrol. Earth Syst. Sci. Discuss., https://doi.org/10.5194/hess-2017-504

Hsu, K., Gao, X., Sorooshian, S., \& Gupta, H.: Precipitation estimation from remotely sensed information using artificial neural networks. J. Appl. Met., 36, 1176-1190, 1997.

Hu, Q, Yang D, Li Z, Mishra A, Wang Y, \& Yang H.: Multi-scale evaluation of six high-resolution satellite monthly rainfall estimates over a humid region in China with dense rain gauges. Int. J. Remote Sens., 35(4), 2014.

Huber, U. M., Bugmann, H. K., \& Reasoner, M. A.: Global change and mountain regions: an overview of current knowledge: Springer, Doderecht, Netherlands, 2006.

Huffman, G., Adler, F., Rudolf, B., Schneider, U., \& Keehn, P.: The Global Precipitation Climatology Project (GPCP) combined precipitation dataset.Bull. MAEr. Meteor. Soc, 78, 5-20, 1997.

Huffman, G., Bolvin, D., Nelkin, E., Wolff, D., Adler, R., Gu, G., Stocker, E.: The TRMM multisatellite precipitation analysis (TMPA): quasi-global, multiyear, combined-sensor precipitation estimates at fine scales. J. Hydrometeorol., 8, 38-55, 2007.

Jiang, S., Ren, L., Hong, Y., Yong, B., Yang, X., Yuan, F., \& Ma, M.: Comprehensive evaluation of multi-satellite precipitation products with a dense rain gauge network and optimally merging their simulated hydrological flows using the Bayesian model averaging method. J. Hydrol., 452, 213-225, 2012.

Joyce, R., Janowiak, J., Arkin, P., \& Xie, P.: CMORPH: a method that produces global precipitation estimates from passive microwave and infrared data at high spatial and temporal resolution. $J$. Hydrometeorol., 5, 487-503, 2004.

Katsanos, D., Retalis, A.,\& Michaelides, S.: Validation of a high-resolution precipitation database (CHIRPS) over Cyprus for a 30-year period. Atmos. Res., 169, 459-464, 2015.

Kiros, G., Shetty, A., \& Nandagiri, L.: Analysis of variability and trends in rainfall over northern Ethiopia. Arab. J.Geosci., 9(6), 451, 2016.

Knapp, K., Ansari, S., Bain, C., Bourassa, M., Dickinson, M., Funk, C., Huffman, G.: Globally gridded satellite observations for climate studies. Bull. Am. Meteorol. Soc., 92, 893-907, 2011.

Love, T., Kumar, V., Xie, P., \& Thiaw, W.:A 20-year daily Africa precipitation climatology using satellite and gauge data. Paper presented at the Conference on Applied Climatology,11-15 January 2004, Seattle, WA, 2004.

Meng, J., Li, L., Hao, Z., Wang, J., \& Shao, Q.: Suitability of TRMM satellite rainfall in driving a distributed hydrological model in the source region of Yellow River. J. Hydrol. 509, 320-332, 2014.

Moriasi, D. N., Arnold, J. G., Van Liew, M. W., Bingner, R. L., Harmel, R. D., \& Veith, T. L.: Model evaluation guidelines for systematic quantification of accuracy in watershed simulations. T.ASABE., 50(3), 885-900, 2007.

Moreno, J. F., Mannaerts, C. M., \& Jetten, V.: Influence of topography on rainfall variability in Santiago Island, Cape Verde. Int. J. Climatol., 34(4), 1081-1097, 2014.

Nyssen, J., Vandenreyken, H., Poesen, J., Moeyersons, J., Deckers, J., Haile, M., Govers, G.: Rainfall erosivity and variability in the Northern Ethiopian Highlands. J. Hydrol., 311, 172-187, 2005.

Ouma, Y. O., Owiti, T., Kipkorir, E., Kibiiy, J., \& Tateishi, R.: Multitemporal comparative analysis of TRMM-3B42 satellite-estimated rainfall with surface gauge data at basin scales: daily, decadal and monthly evaluations. Int. J.Remote Sens., 33(24), 7662-7684, 2012.

Ruelland, D., Ardoin-Bardin, S., Billen, G., and Servat, E.: Sensitivity of a lumped and semidistributed hydrological model to several methods of rainfall interpolation on a large basin in West Africa, J. Hydrol., 361, 96-11, 2008.

Seleshi, Y., \& Zanke, U.: Recent changes in rainfall and rainy days in Ethiopia. Int. J. Climatol., 24(8), 973-983, 2004.

Sunilkumar, K., Narayana Rao, T., Saikranthi, K., \& Purnachandra Rao, M.: Comprehensive evaluation of multisatellite precipitation estimates over India using gridded rainfall data. J.Geophys.Res.- Atmosph., 120(17), 8987-9005, 2015.

Taye, M. T., \& Willems, P.: Identifying sources of temporal variability in hydrological extremes of the upper Blue Nile basin. J. Hydrol., 499, 61-70, 2013.

Thiemig, V., Rojas, R., Zambrano-Bigiarini, M., Levizzani, V., \& De Roo, A.: Validation of satellitebased precipitation products over sparsely gauged African river basins. J. Hydrometeoro., 13(6), 1760-1783, 2012. 
Hydrol. Earth Syst. Sci. Discuss., https://doi.org/10.5194/hess-2017-504

Manuscript under review for journal Hydrol. Earth Syst. Sci.

Discussion started: 29 August 2017

(c) Author(s) 2017. CC BY 4.0 License.

2

Toté, C., Patricio, D., Boogaard, H., van der Wijngaart, R., Tarnavsky, E., \& Funk, C.: Evaluation of Satellite Rainfall Estimates for Drought and Flood Monitoring in Mozambique. Remote Sens., 7(2), 1758, 2015.

4 Van der Ent, R. J., Savenije, H. H., Schaefli, B., \& Steele-Dunne, S. C.: Origin and fate of atmospheric moisture over continents.Water Resour.Re., 46(9), W09525, 2010.

Viste, E., \& Sorteberg, A.: Moisture Transport and Precipitation in Ethiopia. Int. J. Climatol., 33(1), 249-263, 2013.

WMO.: World Meteorological Organization Guide to Hydrological Practices: Data Acquisition and Processing, Analysis, Forecasting and Other Applications. Geneva, Swizerland, 1994.

Worqlul, A, Maathuis, B., Adem, A. A., Demissie, S. S., Langan, S., \& Steenhuis, T. S.: Comparison of rainfall estimations by TRMM 3B42, MPEG and CFSR with ground-observed data for the Lake Tana basin in Ethiopia. Hydrol. Earth Syst. Sci., 18(12), 4871-4881, 2014.

Xie, P., \& Arkin, A.: An Intercomparison of Gauge Observations and Satellite Estimates of Monthly Precipitation. J. Appl. Meteorol., 34 (5), 1143-1160, 1995.

Xie, p., \& Arkin, p.: Global precipitation: a 17-year monthly analysis based on gauge observations, satellite estimates, and numerical model outputs. B. Amr. Meteor. Soc., 78, 2539-2558, 1997.

Xue, X., Hong, Y., Limaye, A. S., Gourley, J. J., Huffman, G. J., Khan, S. I., Chen, S.: Statistical and hydrological evaluation of TRMM-based Multi-satellite Precipitation Analysis over the Wangchu Basin of Bhutan: Are the latest satellite precipitation products 3B42V7 ready for use in ungauged basins? J. Hydrol., 499, 91-99, 2013.

(1)


Hydrol. Earth Syst. Sci. Discuss., https://doi.org/10.5194/hess-2017-504

Manuscript under review for journal Hydrol. Earth Syst. Sci.

Discussion started: 29 August 2017

(c) Author(s) 2017. CC BY 4.0 License.

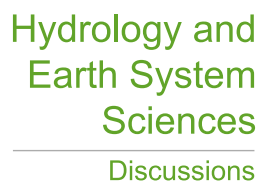

(c) (1)

Table 1: Summary of selected satellite rainfall products for this study (in descending order of spatial

2

resolution)

\begin{tabular}{lllll}
\hline Product & $\begin{array}{l}\text { Temporal } \\
\text { resolution }\end{array}$ & Spatial resolution & Coverage & Starting date \\
\hline CHIRPSv8 & Daily & $0.05^{\circ}$ & $50^{\circ} \mathrm{N}-50^{\circ} \mathrm{S}, 0^{\circ}-360^{\circ} \mathrm{E}$ & 1981 \\
ARCv2 & Daily & $0.1^{\circ}$ & $40^{\circ} \mathrm{N}-40^{\circ} \mathrm{S}, 20^{\circ} \mathrm{W}-55^{\circ} \mathrm{E}$ & 1983 \\
RFEv2 & Daily & $0.1^{\circ}$ & $40^{\circ} \mathrm{N}-40^{\circ} \mathrm{S}, 20^{\circ} \mathrm{W}-55^{\circ} \mathrm{E}$ & 2001 \\
CMORPH & 3 hourly & $0.25^{\circ}$ & Global & 2002 \\
PERSIANN & Daily & $0.25^{\circ}$ & Global & 1983 \\
TRMM 3B42v7 & Daily & $0.25^{\circ}$ & $50^{\circ} \mathrm{N}-50^{\circ} \mathrm{S}, 0^{\circ}-360^{\circ} \mathrm{E}$ & 1998 \\
GPCP & Daily & $1.0^{\circ}$ & Global & 1979 \\
CMAP & pentad & $2.5^{\circ}$ & Global & 1998 \\
\hline
\end{tabular}

4

8

10

12

14

16

18

20

22

28 Table 2: Statistical indices used for the satellite rainfall products performance evaluation 
Hydrol. Earth Syst. Sci. Discuss., https://doi.org/10.5194/hess-2017-504

Manuscript under review for journal Hydrol. Earth Syst. Sci.

Discussion started: 29 August 2017

\begin{tabular}{lcll}
\hline Statistical measure & Equation & Ranges & Perfect score \\
\hline Root Mean Square Error (RMSE) & $\sqrt{1 / N \sum_{i=1}^{n}(y i-\mathrm{xi})^{2}}$ & 0 to $\infty$ & 0 \\
Mean Absolute Error (MAE) & $1 / N \sum|y i-x i|$ & 0 to $\infty$ & 0 \\
Percent of bias (PBIAS) & $\left(\left(\sum \mathrm{yi}-\sum \mathrm{xi}\right) / \sum \mathrm{xi}\right) * 100$ & 0 to $\infty$ & 0 \\
Pearson correlation coefficient (r) & $\frac{\sum(x i-\bar{x})(y i-\bar{y})}{\sqrt{(x i-\bar{x})^{2}} \sqrt{(y i-\bar{y})^{2}}}$ & -1 to 1 & 1
\end{tabular}

Where $\mathrm{xi}$ is observed rainfall from rain gauge, yi is satellite rainfall product, $\mathrm{N}$ is the number of pairs of

2 products, $\bar{x}$ and $\bar{y}$ are the average of observed and satellite rainfall data, respectively.

4

6

8 
Hydrol. Earth Syst. Sci. Discuss., https://doi.org/10.5194/hess-2017-504

Manuscript under review for journal Hydrol. Earth Syst. Sci.

Discussion started: 29 August 2017

(c) Author(s) 2017. CC BY 4.0 License.

Table 3: Average accuracy indicators obtained from monthly comparison

\begin{tabular}{lcccc}
\hline Satellite estimate & PBIAS $(\%)$ & $\mathrm{r}$ & RMSE (mm/month) & MAE (mm/month) \\
\hline CHIRPS & -8 & 0.61 & 17 & 16 \\
ARCv2 & -50 & 0.43 & 112 & 98 \\
RFEv2 & -10 & 0.56 & 23 & 21 \\
CMORPH & 14 & 0.48 & 75 & 29 \\
PERSIANN & -11 & 0.52 & 41 & 23 \\
TRMM & 7 & 0.59 & 32 & 26 \\
GPCP & -27 & 0.36 & 143 & 103 \\
CMAP & -42 & 0.32 & 126 & 83 \\
\hline
\end{tabular}

2

4

6

8

10

12

14

16

18

20

22

24

26 
Hydrol. Earth Syst. Sci. Discuss., https://doi.org/10.5194/hess-2017-504

Manuscript under review for journal Hydrol. Earth Syst. Sci.

Discussion started: 29 August 2017

Table 4: Comparison of satellite and observed aerial rainfalls at basin level with different time scale

\begin{tabular}{clllllllll}
\hline \multirow{2}{*}{ Indices } & Temporal & & & & & & & & \\
PBIAS & CHIRPS & ARC2 & RFEv2 & CMORPH & PERSIANN & TRMM & GPCP & CMAP \\
\hline \multirow{2}{*}{ PBIf } & Daily & -10 & -58 & -8 & 18 & -13 & 11 & -41 & -38 \\
& Monthly & -8 & -41 & -6 & 15 & -11 & 8 & -28 & -33 \\
& Wet season & -6 & -21 & -3 & 11 & -8 & 6 & -19 & -24 \\
& Daily & 0.49 & 0.22 & 0.48 & 0.19 & 0.28 & 0.41 & 0.15 & 0.21 \\
& Monthly & 0.69 & 0.39 & 0.5 & 0.41 & 0.54 & 0.56 & 0.3 & 0.28 \\
& Wet season & 0.88 & 0.41 & 0.72 & 0.55 & 0.64 & 0.7 & 0.36 & 0.39 \\
RMSE & Daily & 36 & 111 & 50 & 42 & 48 & 25 & 89 & 60 \\
(mm) & Monthly & 42 & 178 & 61 & 70 & 49 & 34 & 205 & 80 \\
& Wet season & 79 & 201 & 67 & 112 & 137 & 142 & 395 & 309 \\
MAE & Daily & 19 & 102 & 25 & 39 & 48 & 25 & 79 & 54 \\
$(\mathrm{~mm})$ & Monthly & 41 & 141 & 36 & 68 & 51 & 31 & 131 & 78 \\
& Wet season & 71 & 198 & 68 & 102 & 131 & 123 & 171 & 229 \\
\hline
\end{tabular}

Values in italics indicate acceptable region of PBIAS (-25\% - 25\%) and correlation coefficient $(r>0.5)$

4

6

10 
Hydrol. Earth Syst. Sci. Discuss., https://doi.org/10.5194/hess-2017-504

Manuscript under review for journal Hydrol. Earth Syst. Sci.

Discussion started: 29 August 2017

(c) Author(s) 2017. CC BY 4.0 License.

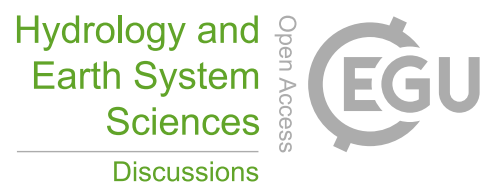

(c) $\underset{\mathrm{BY}}{(-)}$

2

Figure 1: Location map and distribution of rainfall stations in the Upper T-A Basin
4

6

8

10

12 
Hydrol. Earth Syst. Sci. Discuss., https://doi.org/10.5194/hess-2017-504

Hydrology and Manuscript under review for journal Hydrol. Earth Syst. Sci.

Discussion started: 29 August 2017

(c) Author(s) 2017. CC BY 4.0 License.

8

Figure 2: Relationship between rainfall and elevation in the T-A basin 
Hydrol. Earth Syst. Sci. Discuss., https://doi.org/10.5194/hess-2017-504

Manuscript under review for journal Hydrol. Earth Syst. Sci.

Discussion started: 29 August 2017

(c) Author(s) 2017. CC BY 4.0 License.

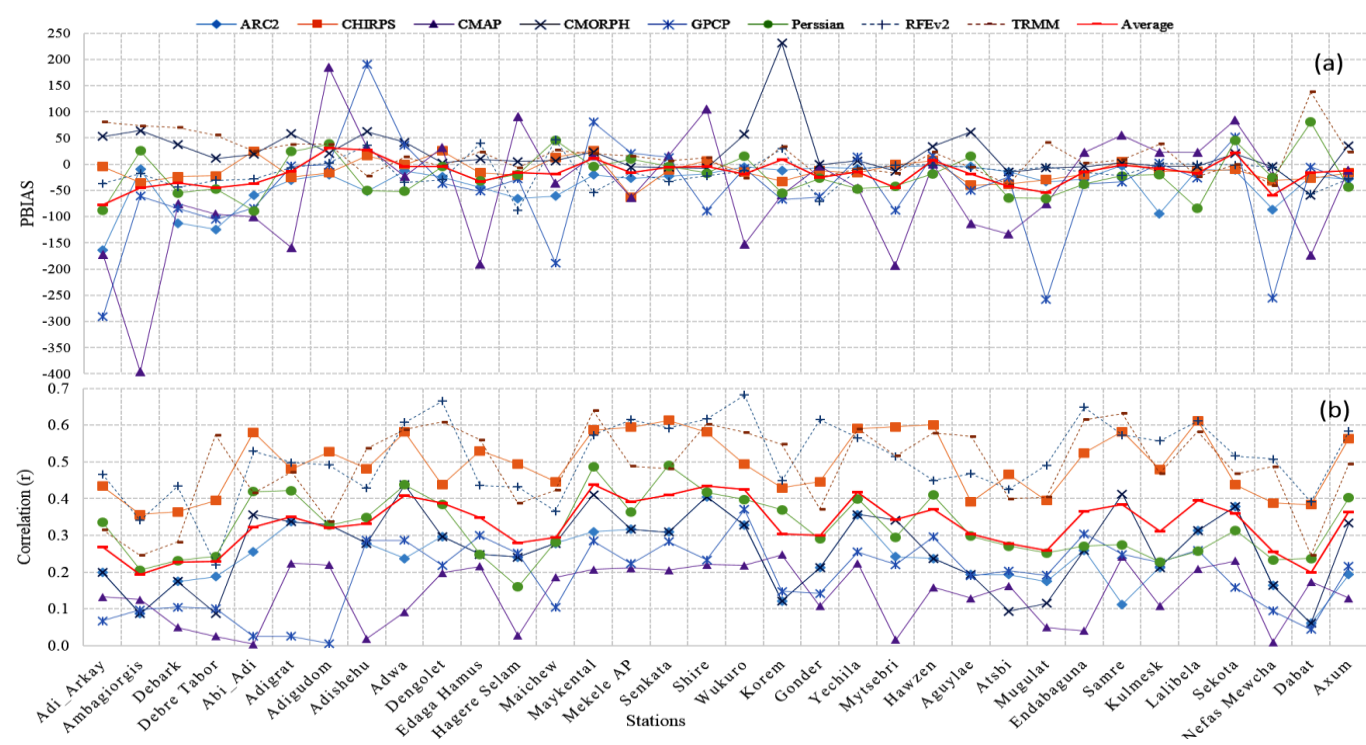

Figure 3: Comparison of daily Satellite rainfall estimate with ground measurements, (a) PBIAS, (b) Correlation (r) 
Hydrol. Earth Syst. Sci. Discuss., https://doi.org/10.5194/hess-2017-504

Hydrology and Manuscript under review for journal Hydrol. Earth Syst. Sci.

Discussion started: 29 August 2017

(c) Author(s) 2017. CC BY 4.0 License.

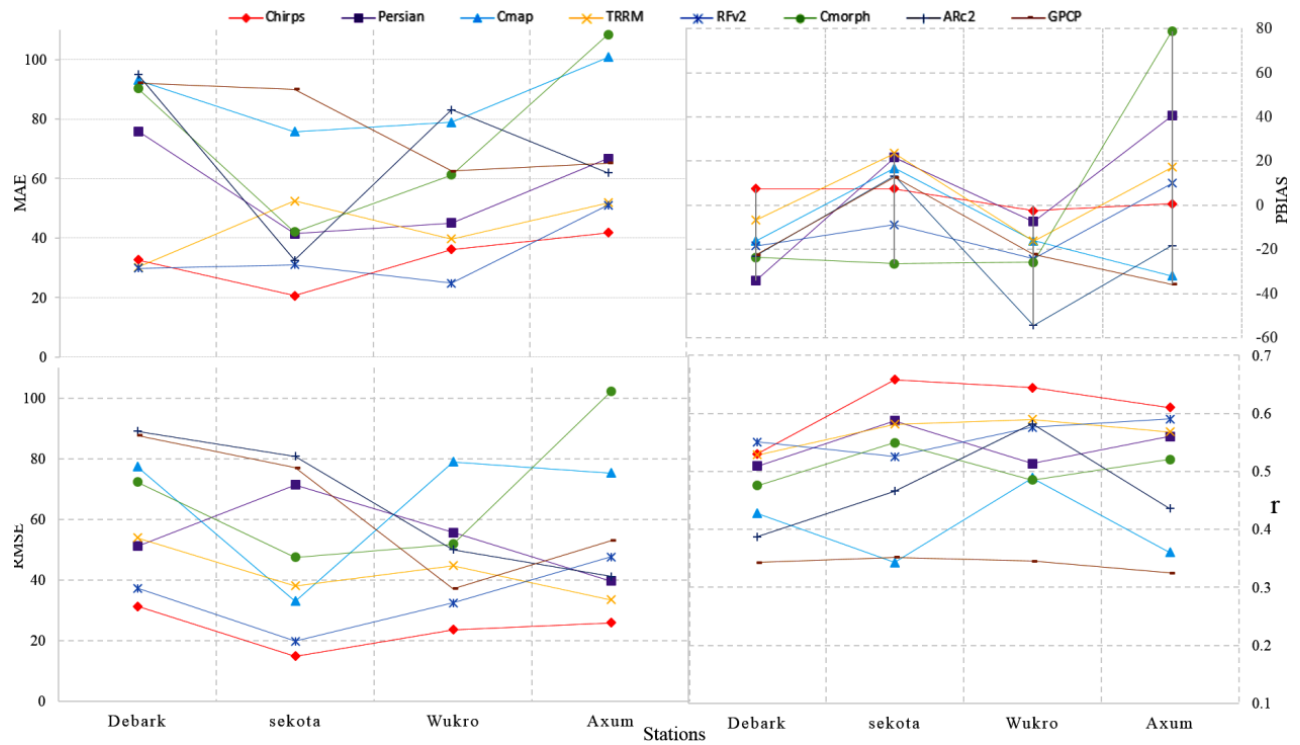

Figure 4: Monthly statistical indices at pixel to point rainfall comparison. 
Hydrol. Earth Syst. Sci. Discuss., https://doi.org/10.5194/hess-2017-504

Hydrology and Manuscript under review for journal Hydrol. Earth Syst. Sci.

Discussion started: 29 August 2017

(c) Author(s) 2017. CC BY 4.0 License.

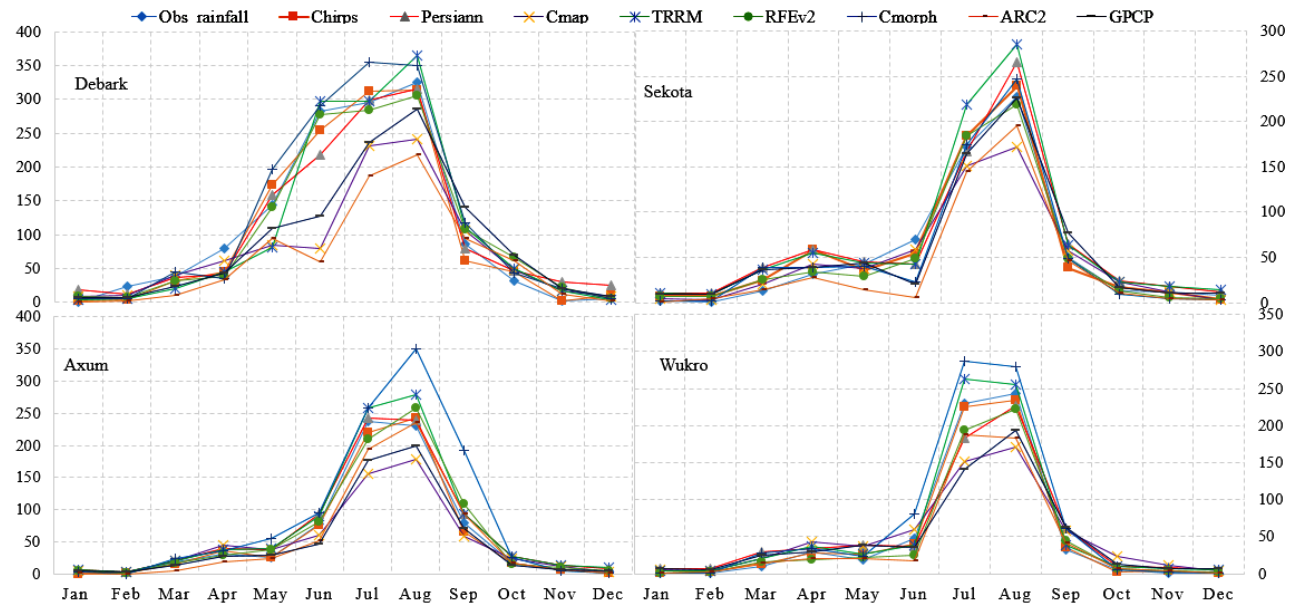

Fig 5: Comparison of mean monthly rainfall (2002-20015) at four representative ground station 
Hydrol. Earth Syst. Sci. Discuss., https://doi.org/10.5194/hess-2017-504

Manuscript under review for journal Hydrol. Earth Syst. Sci.

Discussion started: 29 August 2017

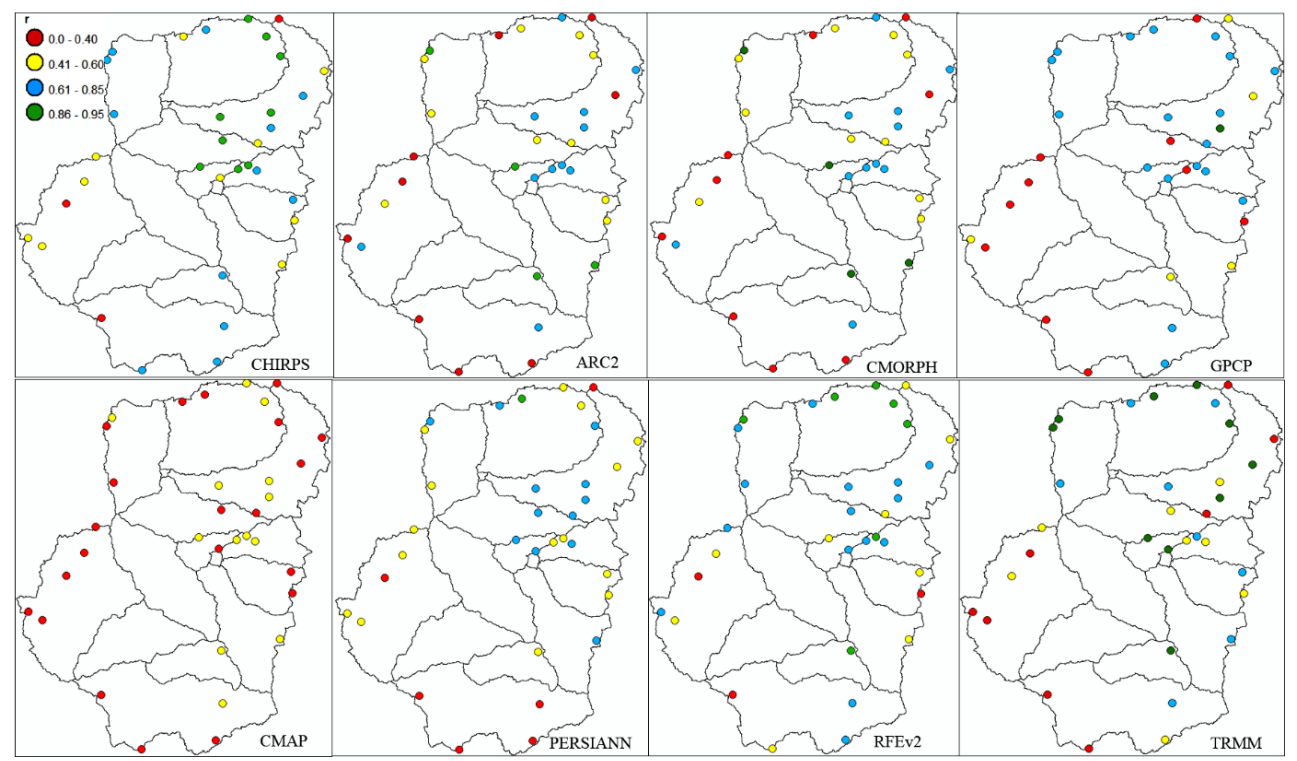

Figure 6: Spatial distribution of correlationcoefficients (r) during the wet season comparison.

4

6

8

10 
Hydrol. Earth Syst. Sci. Discuss., https://doi.org/10.5194/hess-2017-504

Manuscript under review for journal Hydrol. Earth Syst. Sci.

Discussion started: 29 August 2017

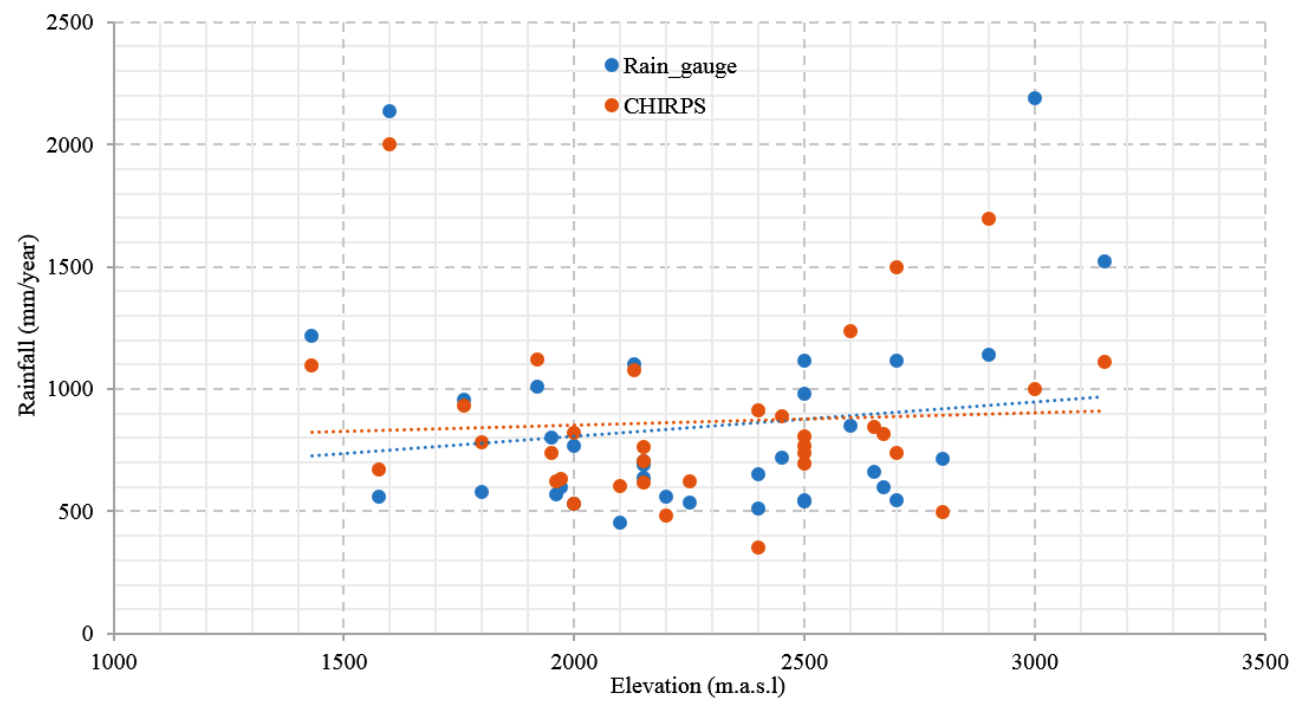

Figure 7: Comparison of annual average rainfall with elevation

4

6

8

10 
Hydrol. Earth Syst. Sci. Discuss., https://doi.org/10.5194/hess-2017-504

Manuscript under review for journal Hydrol. Earth Syst. Sci.

Discussion started: 29 August 2017

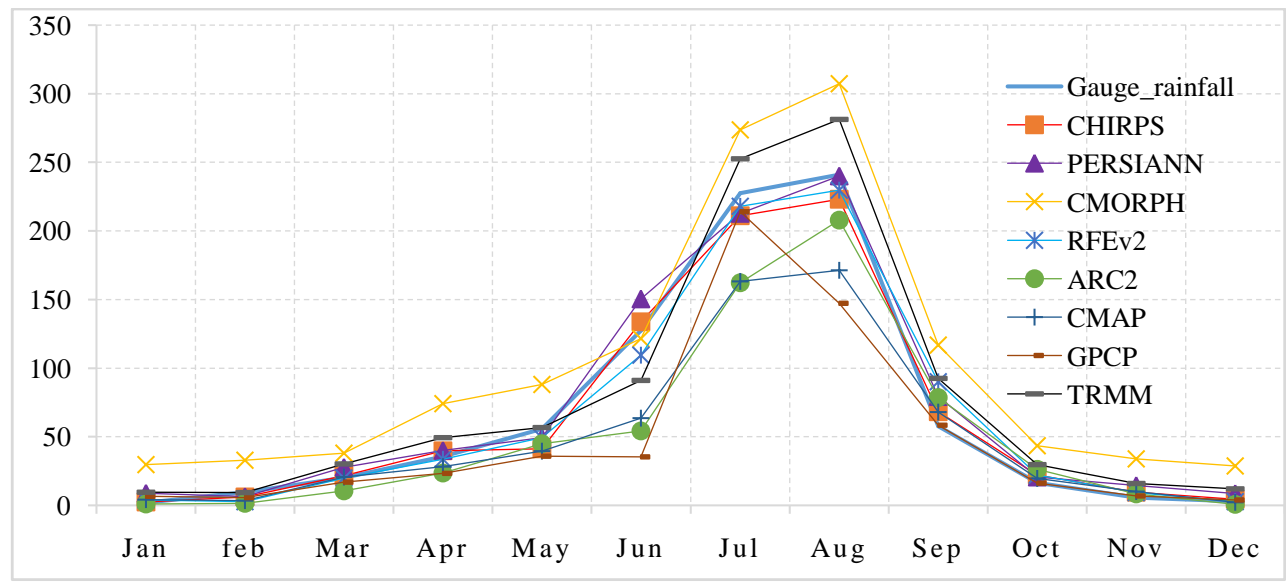

Figure 8: Monthly average satellite estimates and ground rainfall comparison at basin scale

8 
Hydrol. Earth Syst. Sci. Discuss., https://doi.org/10.5194/hess-2017-504

Manuscript under review for journal Hydrol. Earth Syst. Sci.

Discussion started: 29 August 2017

4

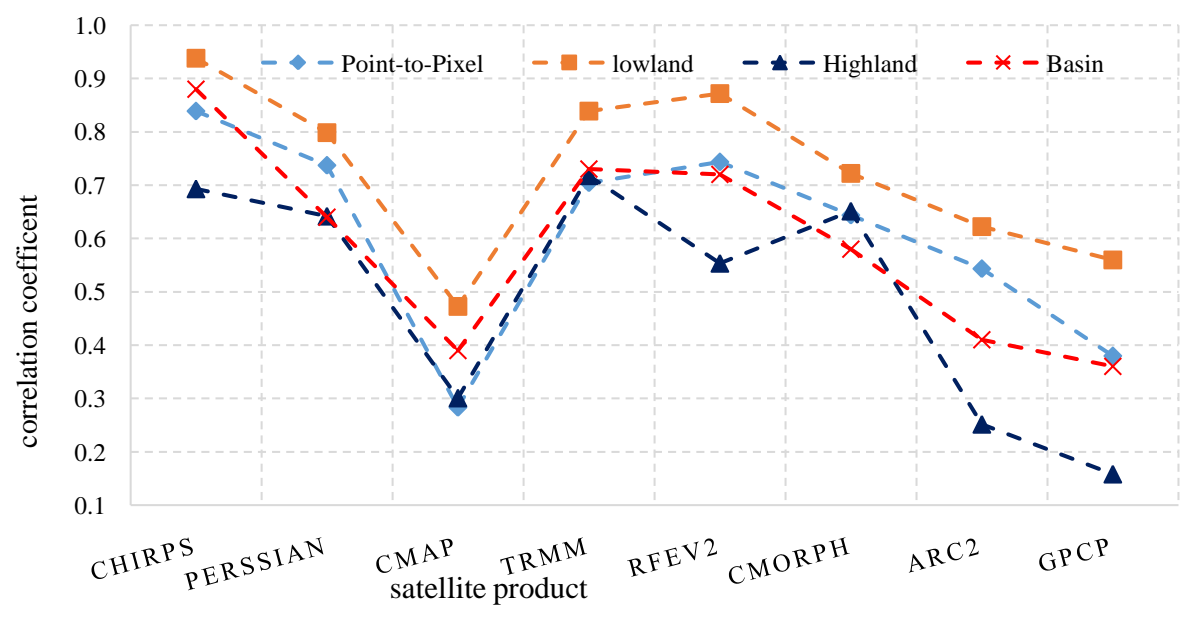

Fig.9: Comparison of seasonal averaged correlation at a pixel, sub-basin, and basin scales
6

8

10

12

14

16 